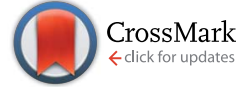

Cite this: RSC Adv., 2017, 7, 15851

Received 17th January 2017 Accepted 6th March 2017

DOI: 10.1039/c7ra00703e

rsc.li/rsc-advances

\section{Reversal aggregation-induced circular dichroism from axial chirality transfer via self-assembled helical nanowires $\dagger$}

\author{
Fandian Meng, Yuan Sheng, Fei Li, Chengjian Zhu, Yiwu Quan* and Yixiang Cheng* \\ Two chiral binaphthyl-based enantiomers, $(R / S)$-7, were designed and synthesized by Sonogashira cross- \\ coupling reaction of AIE-active TPE and O-BOPHY. Interestingly, the resulting $(R / S)-7$ can exhibit \\ emission enlargement response in $\mathrm{DCM}$ /hexane mixtures due to AIE behavior, but fluorescence \\ quenching in $\mathrm{THF} / \mathrm{H}_{2} \mathrm{O}$ mixtures due to $\mathrm{ACQ}$ effect. $(R / S)-7$ can produce gradual reversal $\mathrm{AICD}$ \\ (aggregation-induced circular dichroism) signals from solution to aggregation, which can be attributed \\ to axial chirality transfer to self-assembled helical nanowires in aggregation state.
}

\section{Introduction}

In the past ten years, fluorine-boron hybrid complexes have attracted much attention on the organic functional materials for optoelectronic devices, solar cell, OLED and bioprobes. ${ }^{1}$ It is well known that bis(difluoroboron)-1,2-bis $\{(1 H$-pyrrol-2-2-yl) methylene\}hydrazine (BOPHY) and 4,4-difluoro-4-bora-3a,4adiaza-sindacene (BODIPY) dyes have been regarded as excellent chromophores due to their high quantum yields, sharp fluorescent emission band and narrow absorption. ${ }^{2}$ However, BOPHY and BODIPY dyes often show small Stokes' shift which often causes serious self-reabsorption affecting the optical properties. $^{3}$ It is of great significance to design $\mathrm{D}-\pi-\mathrm{A}$ type molecules and prevent the self-reabsorption via intramolecular energy transfer (IET) mechanism. ${ }^{4}$ Recently, our group reported mirror-image red-color circularly polarized luminescence (CPL) material of chiral BINOL-based $O$-BODIPY enantiomers via IET mechanism from the AIE-active tetraphenyl ethylene (TPE) moiety to the chiral $O$-BODIPY chromophore in DCM/hexane mixtures. ${ }^{5}$

Most organic molecules have aggregation-caused quenching (ACQ) effect which is a harmful photophysical effect on their practical applications. ${ }^{6}$ Since 2001, Tang's group first found a kind of the propeller-shaped silole molecule with aggregationinduced emission (AIE) feature which could successfully solve the problem of ACQ. ${ }^{7}$ Meanwhile, Park and his co-workers also observed a kind of fluorescent organic nanoparticles with aggregation-induced emission enhance (AIEE) response

Key Lab of Mesoscopic Chemistry of MOE, Collaborative Innovation Center of Chemistry for Life Sciences, School of Chemistry and Chemical Engineering, Nanjing University, Nanjing 210093, China. E-mail: yxcheng@nju.edu.cn; quanyiwu@nju. edu.cn

$\dagger$ Electronic supplementary information (ESI) available. See DOI: 10.1039/c7ra00703e behavior in $2002 .{ }^{8}$ Recently, more and more works have been focused on the AIE or AIEE-based functional molecules as optoelectronic devices and biosensors. ${ }^{9}$ Therefore developing tunable aggregation-induced CPL (AICPL) materials based on chiral AIE luminogens have received considerable interest in the aggregate state by choosing various chiral unit and chromophores. But so far there have been only a few reports on AICPL materials based on chiral AIE-active organic fluorescence molecules. Especially, it is quite difficult to adjust and control the CPL signal polarization direction of common chiral organic fluorescence molecules without changing chiral configuration. ${ }^{10}$ Our group reported reversal AICPL signals of chiral binaphthyl-based molecules from cis-conformation in solution to trans-conformation in aggregation state due to the dihedral angle enlargement of two naphthyl rings. ${ }^{\mathbf{1 1}}$

Chiral BINOL-based fluorescence molecules have been successfully used for CPL materials due to high chiral induction feature. Moya's group reported a novel CPL material based on chirality perturbing from BINOL moiety to the achiral chromophore (BODIPY). ${ }^{12}$ So far, there has been no report on reversal CPL signal from solution system to aggregation state via self-assembled helical nanofibers. In this work, we synthesized two chiral binaphthyl-based enantiomers incorporating BODPHY as chromophore and TPE as AIE-active group, which can exhibit AIEE effect in DCM/hexane solution and ACQ effect in $\mathrm{THF} / \mathrm{H}_{2} \mathrm{O}$ solution, but no change for reverse AICPL signals can be observed in different solution system. Interestingly, reversal AICD signals was observed in $\mathrm{THF} / \mathrm{H}_{2} \mathrm{O}$ solutions as the increases of water fraction, which can be attributed to the formation of self-assembled helical nanowires in the aggregation state via axial chirality transfer. ${ }^{10 a, 13}$ Compared with the previous reports on AIE-active TPE-based molecules, almost all of them showed aggregation-induced emission enhancement (AIEE) response behaviors. ${ }^{9 a, 14}$ 


\section{Results and discussion}

The detailed synthesis procedures of $(R / S)-7$ can be obtained by the starting product 2,4-dimethyl-1H-pyrrole via 6 steps in the total yield of $12.3 \%$ as shown in Scheme 1 . Bis(difluoroboron)1,2-bis\{(1H-pyrrol-2-2-yl)methylene $\}$ hydrazine (BOPHY) 3, 4 and 6 were synthesized according to the reported works. ${ }^{10 d, 12,15}$ $(R / S)-\mathbf{5}$ was synthesized from $\mathbf{4}$ and $(R / S)$-BINOL, and $(R / S)-7$ was obtained by palladium-catalyzed Sonogashira coupling reaction of $(R / S)-5$ with 6 in about $64 \%$ yield (ESI $2 \dagger)$. Herein, the designed chiral binaphthyl-based $O$-BOPHY enantiomers are composed of three functional moieties: (i) TPE as AIE-active group and energy transfer part; (ii) BINOL as the chiral source; (iii) BOPHY as the acting chromophore.

The UV-vis absorption of $(R / S)$-7 was carried out in different solution systems of DCM/hexane and $\mathrm{THF} / \mathrm{H}_{2} \mathrm{O}$ mixtures as shown in Fig. 1. $(R / S)-7$ enantiomers show the similar absorption spectra in both $\mathrm{DCM} /$ hexane and $\mathrm{THF} / \mathrm{H}_{2} \mathrm{O}$ solutions and have three main absorption peaks centered at 230, 336 and $500 \mathrm{~nm}$, which can be regarded as the absorption peaks of the binaphthyl, TPE and BOPHY of three functional moieties, respectively. The UV-vis spectra of $(R / S)-7$ did not show obvious change in DCM/hexane mixtures (Fig. 1a), but there appears a little red-shift for TPE (about $6 \mathrm{~nm}$ ) and BOPHY (about $16 \mathrm{~nm}$ ) moieties in $\mathrm{THF} / \mathrm{H}_{2} \mathrm{O}$ mixtures as the increase of the water fraction (Fig. 1b).

In this paper the fluorescence spectra $(R / S)-7$ were excited by using $366 \mathrm{~nm}$ to avoid self-absorption interference due to the small Stokes' shift of BOPHY chromophore. As is evident from Fig. 2, it can be clearly observed that $(R / S)-7$ displays fluorescence emission band at $539 \mathrm{~nm}$ with 0.11 of $\Phi_{\mathrm{F}}$ (fluorescence quantum yield) in DCM solution (Fig. 2a). Upon the addition of the poor solvent hexane, the emissive intensity of $(R / S)-7$
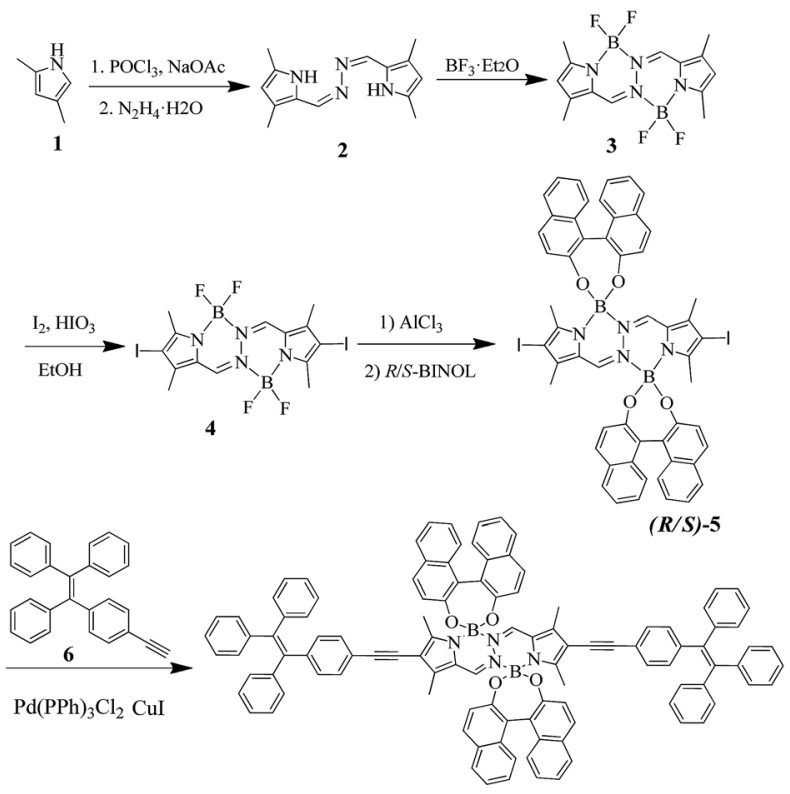

$(R / S)-7$

Scheme 1 Synthesis of (R/S)-7 enantiomers.
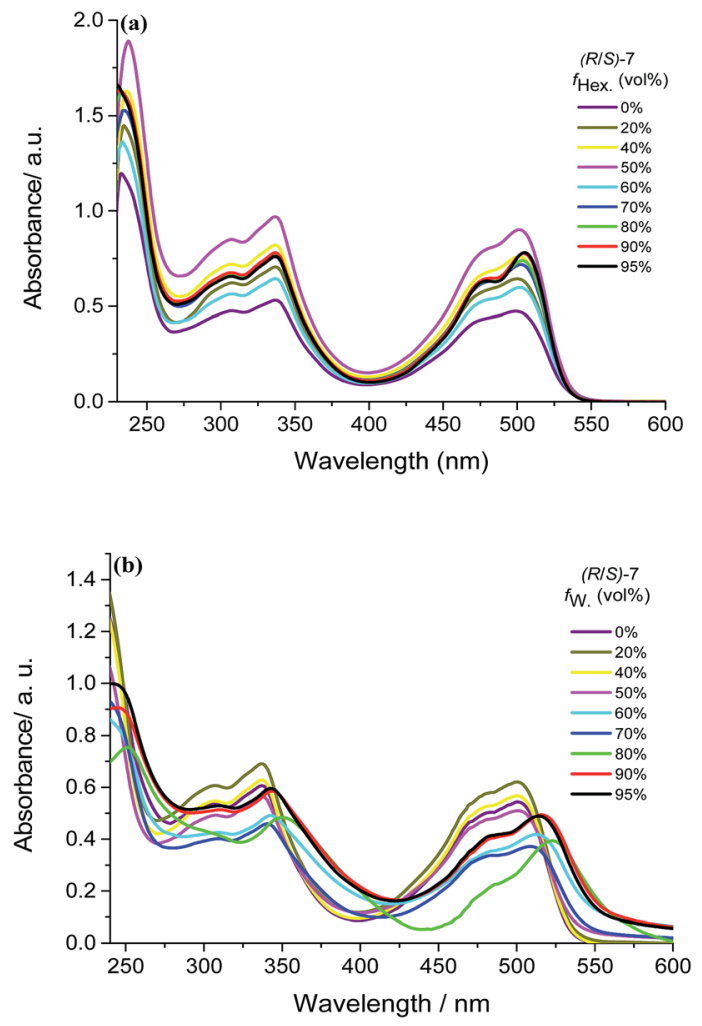

Fig. 1 (a) UV-vis absorption spectra of $(R / S)$-7 in DCM/hexane; (b) UVvis absorption spectra of $(R / S)-7$ in THF/ $/ \mathrm{H}_{2} \mathrm{O}\left(1.0 \times 10^{-5} \mathrm{~mol} \mathrm{~L}^{-1}\right) . f_{\mathrm{HEX}}$ is the volume fraction of hexane, $f_{\mathrm{w}}$ is the volume fraction of water.

gradually enhances with $5 \mathrm{~nm}$ blue-shift at $95 \%$ hexane fraction, the $\Phi_{\mathrm{F}}$ value can reach as high as 0.31 and 2.94-fold higher than that in DCM solution. Meanwhile, $(R / S)-7$ in THF solution has similar fluorescence emission at $538 \mathrm{~nm}$ with 0.07 of $\Phi_{\mathrm{F}}$. Interestingly, $(R / S)-7$ shows obvious fluorescence quenching response as the increase of water fraction (Fig. 2b), and almost no fluorescence emission signal could be observed at $f_{\mathrm{w}}=95 \%$, which can be regarded as ACQ effect. Based on the results of the dynamic light scattering (DLS) measurement (ESI Fig. S1†), we found the particle size of $(R / S)-7$ in THF/water mixtures enlarged from $64.64 \mathrm{~nm}$ at $f_{\mathrm{w}}=60 \%$ to $556.33 \mathrm{~nm}$ at $f_{\mathrm{w}}=95 \%$, indicating that $(R / S)-7$ aggregates produce the solid precipitate in high water fraction.

On the contrary, $(R / S)-7$ can still keep the stable nanoaggregates with a mean diameter of $9.05 \mathrm{~nm}$ at $95 \%$ in DCM/ hexane solution system. Therefore, the morphologies of aggregates in THF/water mixtures were performed by using with scanning electron microscope (SEM). When the fraction of the water is below $70 \%,(S)-7$ forms nanorods (Fig. 3, upper). We are very pleased to find that $(S)-7$ can self-assemble to left-handed helical nanowires with length up to micrometers at $5 \mathrm{vol} \% f_{\mathrm{w}}$ (Fig. 3, lower).

Herein, we further studied the circular dichroism (CD) spectra to investigate the chirality change feature of $(R / S)-7$ from solution to nanoaggregate. The enantiomeric $(R)-7$ and $(S)-7$ can exhibit excellent mirror CD signals in DCM and THF solution (Fig. 4), respectively. Similar to the UV-vis spectra, the CD spectra have 

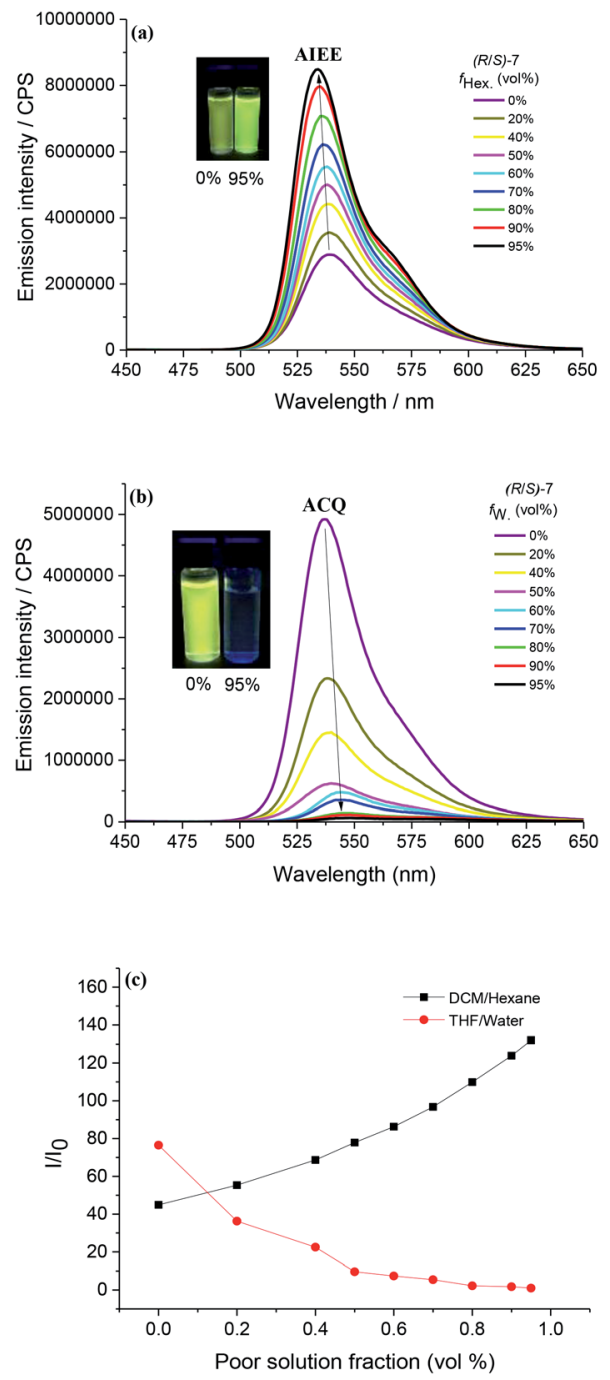

Fig. 2 (a) Fluorescence spectra of $(R / S)$-7 in DCM/hexane; (b) fluorescence spectra of $(R / S)-7$ in $\mathrm{THF} / \mathrm{H}_{2} \mathrm{O}$; (c) plot of $\left(I / I_{0}\right)$ values versus the compositions of the poor solvent fractions $\left(1.0 \times 10^{-5} \mathrm{~mol} \mathrm{~L}^{-1}\right)$.

three main absorption signals-about $240 \mathrm{~nm}$ for binaphthyl unit, about $340 \mathrm{~nm}$ for TPE unit and about $500 \mathrm{~nm}$ for BOPHY unit, which indicates that the chirality of binaphthyl unit can effectively transfer to the AIE-active group (TPE) and chromophore moiety (BOPHY). In DCM/hexane mixtures, only the intensity of CD signals at $537 \mathrm{~nm}$ from the CD absorption of BOPHY unit shows the gradual decrease as the increase of hexane fraction (Fig. 4a). The $g_{\text {abs }}$ compound $(R)-7$ declined from $7.4 \times 10^{-4}$ to $3.1 \times 10^{-4}$, when the fraction of poor solution increases from $0 \%$ to $95 \%$. For $\mathrm{THF} /$ water solution, almost no change in $\mathrm{CD}$ absorption spectra of $(R / S)-7$ can be observed before $60 \%$ water fraction. Interestingly, aggregation-induced CD signals of $(R / S)-7$ exhibit great difference from the Cotton effect peak of BOPHY unit situated at about $490 \mathrm{~nm}$. As the increase of water fraction to 95\%, AICD signals appear reversal and redshift to $520 \mathrm{~nm}$ (Fig. 4b and c), which may be attributed to axial chirality transfer to self-assembled helical nanowires in aggregation state (Fig. 3). ${ }^{\mathbf{1 2}}$ Most importantly, the $g_{\text {abs }}$ of $(R)-7$ also shows reverse change
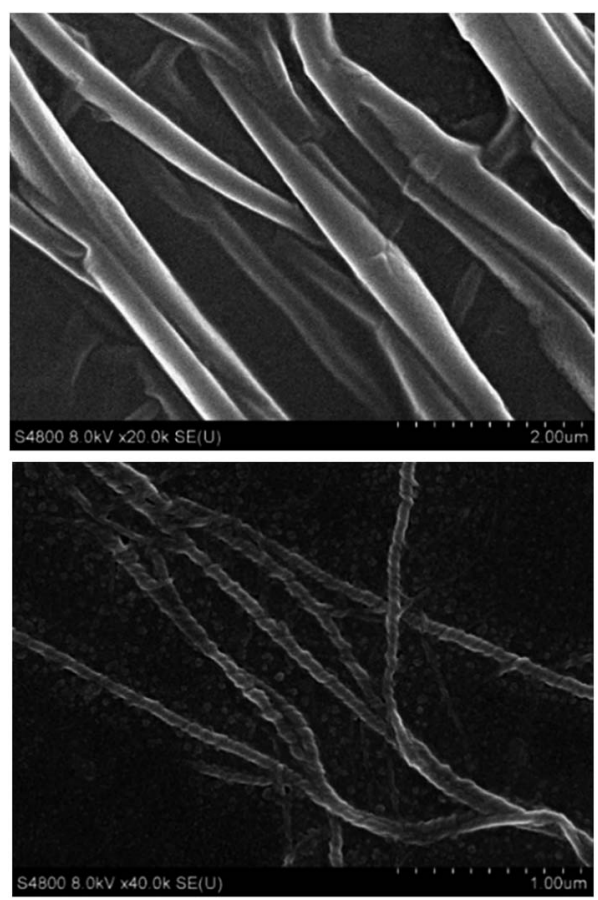

Fig. 3 SEM images of (S)-7 obtained from THF/water (40/60, upper, 5/ 95, lower, v/v).

from $4.0 \times 10^{-4}$ to $-4.1 \times 10^{-4}$ while the fraction of poor solution increases from $0 \%$ to $95 \%$ (Fig. $4 \mathrm{~b}$ and c).

The interesting AICD response behaviour for $(R / S)-7$ in the maximal absorption band demonstrates that the chirality of binaphthyl moiety can induce the BOPHY chromophore in its ground state, which inspired us to further investigate their CPL property. As is evident from Fig. 5, $(R / S)$-7 can show mirrorimage CPL signals centered at about $550 \mathrm{~nm}$ from BOPHY chromophore in both DCM and THF solution. Upon addition of poor solvent, almost no change can be observed for the CPL spectra of $(R / S)-7$ in DCM/hexane mixtures, which is similar to CD spectra. But while the fraction of hexane exceeds $90 \%, \mathrm{CPL}$ signals the $g$-values $\left(g_{\text {lum }}\right)$ of $(R / S)-7$ have a slight decrease from $5.4 \times 10^{-4}$ to $2.7 \times 10^{-4}$. For $\mathrm{THF} / \mathrm{H}_{2} \mathrm{O}$ solution system, we found the $g_{\text {lum }}$ of $(R / S)-7$ can reach as high as $5.5 \times 10^{-4}$ and show no obvious change when the water fraction is below $40 \%$. On the contrary, the CPL signal of $(R / S)-7$ almost disappears after the water fraction is over $60 \%$, which is also similar to fluorescence quenching behaviour (ACQ effect). The reason may be attributed to the formation of the solid precipitate at high water fraction, which leads to very weak fluorescence emission (Fig. 2b). In our previous report, chiral BINOL-based O-BODIPY enantiomers incorporating TPE as AIE-active group also showed on change on the chiroptical properties of CD and CPL either in DCM solution system or aggregate state in DCM/hexane. ${ }^{5}$

\section{Experimental section}

\section{Materials and measurements}

All reagents and solvents were purchased from commercial sources and analytical grade reagent. NMR spectra were 

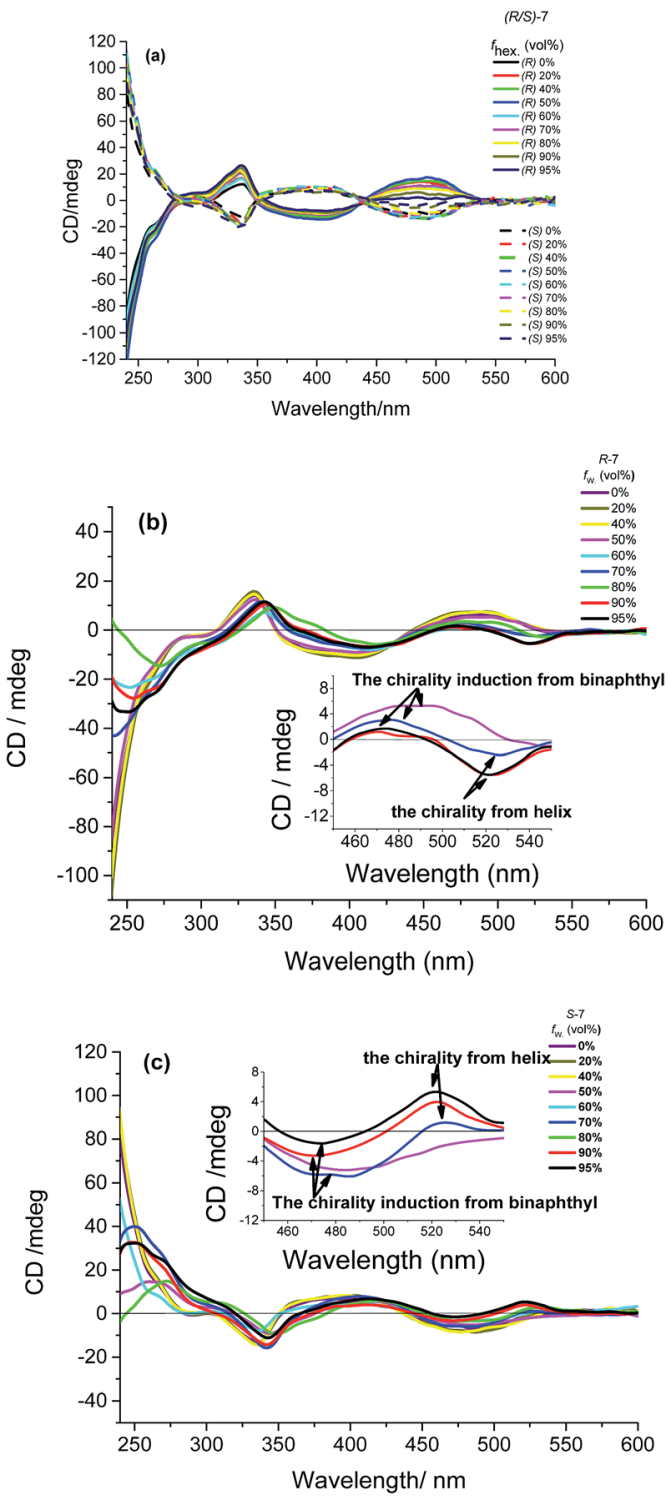

Fig. 4 CD spectra of (R/S)-7: (a) in DCM/hexane mixtures; (b) and (c) in $\mathrm{THF} / \mathrm{H}_{2} \mathrm{O}$ mixtures $\left(1.0 \times 10^{-5} \mathrm{~mol} \mathrm{~L}^{-1}\right)$.

recorded on Bruker Avance 400 spectrometer, using TMS as an internal standard. Fluorescence spectra recorded with an RF5301PC spectrometer. UV-vis spectra and circular dichroism (CD) were obtained on JASCO J-810 spectropolarimeter. Circularly polarized luminescence (CPL) spectra were acquired using the JASCO CPL-200 spectrofluoropolarimeter. Elemental analysis was performed on an Elementar Vario MICRO analyzer. All optical measurements were investigated in THF and THF/water mixtures with a uniform concentration $\left(1.0 \times 10^{-5} \mathrm{~mol} \mathrm{~L}^{-1}\right)$. The level of CPL properties is evaluated by the luminescence dissymmetry factor $\left(g_{\text {lum }}\right)$, which is calculated as $g_{\text {lum }}=2\left(I_{\mathrm{L}}-I_{\mathrm{R}}\right) /$ $\left(I_{\mathrm{L}}+I_{\mathrm{R}}\right)=2 \Delta I / I$, where $I_{\mathrm{L}}$ and IR represent the emission intensities of left and right circularly polarized luminescence, respectively. Experimentally, the value of glum is calculated by $\Delta I / I=[$ ellipticity/(32 980/ln 10)]/(unpolarized PL intensity) at the CPL extremum.
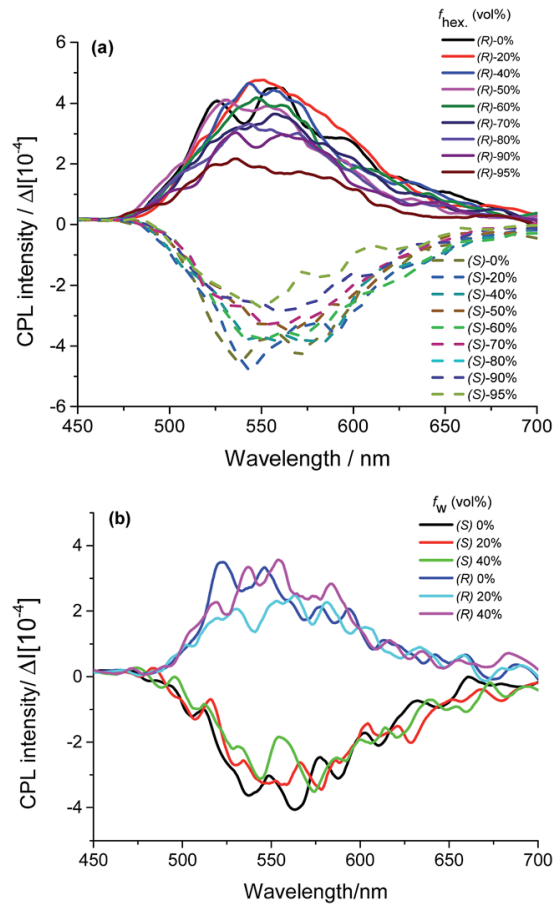

Fig. $5 \mathrm{CPL}$ spectra of $(R)-7$ and (S)-7 in DCM/hexane mixtures (a) and $\mathrm{THF} / \mathrm{H}_{2} \mathrm{O}$ mixtures (b) $\left(1.0 \times 10^{-5} \mathrm{~mol} \mathrm{~L}^{-1}\right)$.

Quantum yields were determined by the optically dilute relative method using the following equation: $\Phi_{\mathrm{S}}=\Phi_{\mathrm{R}} \times\left[\left(I_{\mathrm{S}} \times\right.\right.$ $\left.\left.A_{\mathrm{R}}\right) /\left(I_{\mathrm{R}} \times A_{\mathrm{S}}\right)\right]\left[\left(n_{\mathrm{S}}\right)^{2} /\left(n_{\mathrm{R}}\right)^{2}\right]$ where $\Phi_{\mathrm{S}}$ is the quantum yield of the lanthanide complex, $\Phi_{\mathrm{R}}$ is the quantum yield of the reference, $A$ is the absorbance at the excitation wavelength, $I$ is the relative intensity of the excitation light at the same wavelength, $n$ is the refractive index, and the subscripts " $S$ " and " $R$ " refer to sample and reference, respectively. In this case, quinine sulfate in $0.5 \mathrm{M}$ sulfuric acid was used as reference $\left(\Phi_{\mathrm{R}}=0.55\right)$.

\section{Synthesis of $(R / S)-5$}

A mixture of 4 (464 $\mathrm{mg}, 1 \mathrm{mmol})$, and aluminum chloride (633 $\mathrm{mg}, 4 \mathrm{mmol})$ in dry $\mathrm{CH}_{2} \mathrm{Cl}_{2}(20 \mathrm{~mL})$, was reflux until reaction completion (reaction monitoring by TLC), then, a solution of the corresponding enantiopure 1,1'-bi(2-naphthol) $((1 R)$-BINOL or $(1 S)$-BINOL, $858 \mathrm{mg}, 3 \mathrm{mmol})$ in anhydrous acetonitrile $(10 \mathrm{~mL})$ was added dropwise. The resulting mixture was stirred at room temperature for additional $6 \mathrm{~h}$, washed with brine $(1 \times 10 \mathrm{~mL})$ and dried over anhydrous $\mathrm{Na}_{2} \mathrm{SO}_{4}$. After filtration and solvent evaporation under reduced pressure, the obtained residue was purified by flash chromatography (petroleum ether) to afford 5 as an orange solid (318 mg, 35\%). ${ }^{1} \mathrm{H}$ NMR (300 MHz, $\left.\mathrm{CDCl}_{3}\right): \delta 8.84(\mathrm{~m}, 4 \mathrm{H}), 8.04(\mathrm{~m}, 4 \mathrm{H}), 7.79-7.44$ (m, 14H), $7.04(\mathrm{~m}, 4 \mathrm{H}), 2.14(\mathrm{~s}, 6 \mathrm{H}), 2.04(\mathrm{~s}, 6 \mathrm{H})$.

\section{Synthesis of $(R / S)-7$}

A mixture of compound $(R / S)-5$ (200 mg, $0.18 \mathrm{mmol}), 6$ (138.33 mg, $0.39 \mathrm{mmol}), \mathrm{Pd}\left(\mathrm{PPh}_{3}\right)_{2} \mathrm{Cl}_{2}$ (5\% mmol), CuI (5\% $\mathrm{mmol})$ were added to THF $(20 \mathrm{~mL})$ and $\mathrm{Et}_{3} \mathrm{~N}(10 \mathrm{~mL})$ under nitrogen atmosphere. The reaction mixture was stirred at $80{ }^{\circ} \mathrm{C}$ 
for $36 \mathrm{~h}$. After cooling to room temperature, the solvent was removed under reduced pressure. The residue was purified by column chromatography deactivated basic alumina (petroleum ether/dichloromethane, 4/1) to afford $(R / S)-7$ as a red solid.

$(R)-7:(176 \mathrm{mg}, 62.1 \%){ }^{1} \mathrm{H}$ NMR (300 MHz, $\left.\mathrm{CDCl}_{3}\right) \delta 7.93(\mathrm{~m}$, $6 \mathrm{H}), 7.84(\mathrm{~d}, J=8.1 \mathrm{~Hz}, 2 \mathrm{H}), 7.73(\mathrm{~d}, J=8.8 \mathrm{~Hz}, 2 \mathrm{H}), 7.49(\mathrm{~d}, J=$ $8.7 \mathrm{~Hz}, 2 \mathrm{H}), 7.36(\mathrm{~m}, 8 \mathrm{H}), 7.21-6.94(\mathrm{~m}, 42 \mathrm{H}), 6.88(\mathrm{~d}, J=8.7 \mathrm{~Hz}$, 2H), $1.92(\mathrm{~s}, 6 \mathrm{H}), 1.64(\mathrm{~s}, 6 \mathrm{H}) .{ }^{13} \mathrm{C} \mathrm{NMR}(75 \mathrm{MHz}), \delta$ 154.10, 153.14, 152.53, 143.72, 143.43, 143.38, 143.27, 141.54, 141.16, $140.14,136.09,133.47,133.01,131.31,131.26,131.24,130.54$, 130.22, 130.19, 129.93, 129.78, 128.14, 128.00, 127.78, 127.68, $127.61,127.21,126.61,126.55,126.53,125.90,125.57,124.11$, $123.73,122.69,122.59,122.20,121.96,121.85,121.03,112.92$, 95.37, 81.59, 29.67, 29.63, 13.21, 9.85. Anal. calcd for $\mathrm{C}_{110} \mathrm{H}_{76} \mathrm{~B}_{2} \mathrm{~N}_{4} \mathrm{O}_{4}$ : C, 85.82; H, 4.98. Found: C, 85.80; H, 5.02. MS (ESI, $m / z): 1539.76[\mathrm{M}+\mathrm{H}]^{+}$.

$(S)-7:$ (182 mg, 64.2\%) anal. calcd for $\mathrm{C}_{110} \mathrm{H}_{76} \mathrm{~B}_{2} \mathrm{~N}_{4} \mathrm{O}_{4}: \mathrm{C}$, 85.82; H, 4.98. Found: C, 85.79; H, 4.99. MS (ESI, $\mathrm{m} / \mathrm{z}$ ): 1539.76 $[\mathrm{M}+\mathrm{H}]^{+}$.

\section{Conclusion}

In summary, the chiral BOPHY-based enantiomers incorporating TPE group can exhibit emission enlargement response in DCM/hexane due to AIE behavior, but fluorescence quenching in $\mathrm{THF} / \mathrm{H}_{2} \mathrm{O}$ due to ACQ effect. Reversal AICD signals can be observed from solution to aggregation only in $\mathrm{THF} / \mathrm{H}_{2} \mathrm{O}$ due to axial chirality transfer to self-assembled helical nanowires in aggregation state. The mirror-image CPL signals can be detected in DCM/hexane and low water fraction of $\mathrm{THF} / \mathrm{H}_{2} \mathrm{O}$.

\section{Acknowledgements}

We would like to thank Prof. Zhiyong Tang at NCNST for their kind help on CPL measurement. This work was supported by the National Natural Science Foundation of China (21474048, 21674046, 51673093).

\section{Notes and references}

1 (a) X. Wang, H. Liu, J. Cui, Y. Wu, H. Lu, J. Lu, Z. Liu and W. He, New J. Chem., 2014, 38, 1277; (b) R. S. Singh, M. Yadav, R. K. Gupta, R. Pandey and D. S. Pandey, Dalton Trans., 2013, 42, 1696; (c) S. Guieu, F. Cardona, J. Rocha and A. M. S. Silva, New J. Chem., 2014, 38, 5411; (d) A. Haefele, C. Zedde, P. Retailleau, G. Ulrich and R. Ziessel, Org. Lett., 2010, 12, 1672; (e) Y. Kubota, Y. Sakuma, K. Funabiki and M. Matsui, J. Phys. Chem. A, 2014, 118, 8717.

2 (a) Q. Huaulmé, A. Mirloup, P. Retailleau and R. Ziessel, Org. Lett., 2015, 17, 2246; (b) A. Mirloup, Q. Huaulmé, N. Leclerc, P. Lévêque, T. Heiser, P. Retailleaud and R. Ziessel, Chem. Commun., 2015, 51, 14742; (c) I. S. Tamgho, A. Hasheminasab, J. T. Engle, V. N. Nemykin and C. J. Ziegler, J. Am. Chem. Soc., 2014, 136, 5623; (d) H. M. Rhoda, K. Chanawanno, A. J. King, Y. V. Zatsikha, C. J. Ziegler and V. N. Nemykin, Chem.-Eur. J., 2015, 21, 18043.
3 (a) A. Brzeczek, K. Piwowar, W. Domagala, M. M. Mikołajczyk, K. Walczakb and P. Wagner, RSC Adv., 2016, 6, 36500; (b) J. Liao, Y. Xu, H. Zhao, Y. Wang, W. Zhang, F. Peng, S. Xie and X. Yang, RSC Adv., 2015, 5, 86453; (c) A. M. Courtis, S. A. Santos, Y. Guan, J. A. Hendricks, B. Ghosh, D. M. Szantai-Kis, S. A. Reis, J. V. Shah and R. Mazitschek, Bioconjugate Chem., 2014, 25, 1043; (d) J. Liao, Y. Wang, Y. Xu, H. Zhao, X. Xiao and $\mathrm{X}$. Yang, Tetrahedron, 2015, 71, 5078.

4 (a) B. Cosut, Dyes Pigm., 2014, 100, 11; (b) L. Kong, H. L. Wong, A. Y. Y. Tam, W. H. Lam, L. Wu and V. W. W. Yam, ACS Appl. Mater. Interfaces, 2014, 6, 1550; (c) M. Klaper and T. Linker, J. Am. Chem. Soc., 2015, 137, 13744; (d) C. Sohn, J. Jeong, J. H. Lee, B. H. Choi, H. Hwang, G. T. Bae, K. M. Lee and M. H. Park, Dalton Trans., 2016, 45, 5825; (e) E. Sen, K. Meral and S. Atılgan, Chem.-Eur. J., 2016, 22, 736; (f) M. J. Leonardi, M. R. Topka and P. H. Dinolfo, Inorg. Chem., 2012, 51, 13114; $(g)$ F. Sozmen, B. S. Oksal, O. A. Bozdemir, O. Buyukcakir and E. U. Akkaya, Org. Lett., 2012, 14, 5286.

5 (a) M. Baglan, S. Ozturk, B. Gür, K. Meral, U. Bozkaya, O. A. Bozdemir and S. Atlgan, RSC Adv., 2013, 3, 15866; (b) S. Guo, L. Ma, J. Zhao, B. Küçüköz, A. Karatay, M. Hayvali, H. G. Yaglioglu and A. Elmali, Chem. Sci., 2014, 5, 489; (c) A. Harriman, G. Izzet and R. Ziesse, J. Am. Chem. Soc., 2006, 128, 10868.

6 (a) X. Ma, R. Sun, J. Cheng, J. Liu, F. Gou, H. Xiang and X. Zhou, J. Chem. Educ., 2016, 93, 345; (b) M. Yang, D. Xu, W. Xi, L. Wang, J. Zheng, J. Huang, J. Zhang, H. Zhou, J. Wu and Y. Tian, J. Org. Chem., 2013, 78, 10344.

7 J. Luo, Z. Xie, J. W. Y. Lam, L. Cheng, H. Chen, C. Qiu, H. S. Kwok, X. Zhan, Y. Liu, D. Zhu and B. Z. Tang, Chem. Commun., 2001, 1740.

8 B. K. An, S. K. Kwon, S. D. Jung and S. Y. Park, J. Am. Chem. Soc., 2002, 124, 14410.

9 (a) J. Mei, N. L. C. Leung, R. T. K. Kwok, J. W. Y. Lam and B. Z. Tang, Chem. Rev., 2015, 115, 11718; (b) P. Krukowski, T. Tsuzuki, Y. Minagawa, N. Yajima, S. Chaunchaiyakul, M. Akai-Kasaya, A. Saito, Y. Miyake, M. Katayama and Y. Kuwahara, J. Phys. Chem. C, 2016, 120, 3964; (c) J. Xiong, W. Xie, J. Sun, J. Wang, Z. Zhu, H. Feng, D. Guo, H. Zhang and Y. Zheng, J. Org. Chem., 2016, 81, 3720; (d) Z. Zhu, J. Qian, X. Zhao, W. Qin, R. Hu, H. Zhang, D. Li, Z. Xu, B. Z. Tang and S. He, ACS Nano, 2016, 10, 588; (e) R. Hu, N. L. C. Leung and B. Z. Tang, Chem. Soc. Rev., 2014, 43, 4494; (f) X. Zhang, K. Wang, M. Liu, X. Zhang, L. Tao, Y. Chen and Y. Wei, Nanoscale, 2015, 7, 11486; $(g)$ L. Liu, B. Wu, P. Yu, R. Zhuo and S. Huang, Polym. Chem., 2015, 6, 5185.

10 (a) J. Liu, H. Su, L. Meng, Y. Zhao, C. Deng, J. C. Y. Ng, P. Lu, M. Faisal, J. W. Y. Lam, X. Huang, H. Wu, K. S. Wong and B. Z. Tang, Chem. Sci., 2012, 3, 2737; (b) Q. Ye, D. Zhu, H. Zhang, X. Lu and Q. Lu, J. Mater. Chem. C, 2015, 3, 6997; (c) R. Tempelaar, A. Stradomska, J. Knoester and F. C. Spano, J. Phys. Chem. B, 2011, 115, 10592; (d) S. Zhang, Y. Wang, F. Meng, C. Dai, Y. Cheng and C. Zhu, Chem. Commun., 2015, 51, 9014; (e) T. Ikeda, T. Masuda, 
T. Hirao, J. Yuasa, H. Tsumatori, T. Kawai and T. Haino, Chem. Commun., 2012, 48, 6025; $(f)$ J. Kumar, H. Tsumatori, J. Yuasa, T. Kawai and T. Nakashima, Angew. Chem., Int. Ed., 2015, 54, 5943.

11 Y. Sheng, D. Shen, W. Zhang, H. Zhang, C. Zhu and Y. Cheng, Chem.-Eur. J., 2015, 21, 13196.

12 E. M. Sánchez-Carnerero, F. Moreno, B. L. Maroto, A. R. Agarrabeitia, M. J. Ortiz, B. G. Vo, G. Muller and S. de la Moya, J. Am. Chem. Soc., 2014, 136, 3346.

13 (a) T. Kaseyama, S. Furumi, X. Zhang, K. Tanaka and M. Takeuchi, Angew. Chem., Int. Ed., 2011, 50, 3684; (b) L. Wang, N. Suzuki, J. Liu, T. Matsuda, N. A. A. Rahim, W. Zhang, M. Fujiki, Z. Zhang, N. Zhou and X. Zhu, Polym.
Chem., 2014, 5, 5920; (c) M. Hentschel, V. E. Ferry and A. P. Alivisatos, ACS Photonics, 2015, 2, 1253.

14 (a) L. He, L. Li, X. Liu, J. Wang, H. Huang and W. Bu, Polym. Chem., 2016, 7, 3722; (b) X. Du, J. Qi, Z. Zhang, D. Ma and Z. Y. Wang, Chem. Mater., 2012, 24, 2178; (c) S. Mi, J. Wu, J. Liu, Z. Xu, X. Wu, G. Luo, J. Zheng and C. Xu, ACS Appl. Mater. Interfaces, 2015, 7, 27511.

15 (a) X. Liu, H. Nan, W. Sun, Q. Zhang, M. Zhan, L. Zou, Z. Xie, X. Li, C. Lu and Y. Cheng, Dalton Trans., 2012, 41, 10199; (b) C. Dai, D. Yang, W. Zhang, B. Bao, Y. Cheng and L. Wang, Polym. Chem., 2015, 6, 3962; (c) C. Yu, L. Jiao, P. Zhang, Z. Feng, C. Cheng, Y. Wei, X. Mu and E. Hao, Org. Lett., 2014, 16, 3048. 